\title{
Adoption of Public Health Readiness Guidelines for Meaningful Use
}

\author{
Eunice R. Santos*, Wesley McNeely, Biru Yang and Raouf R. Arafat
}

Office of Surveillance and Public Health Preparedness, Houston Health Department, Houston, TX, USA

\section{Objective}

To describe the challenges and lessons learned for public health and providers to successfully implement public health Meaningful Use readiness guidelines and navigate from intent to submission of production data while simultaneously upgrading surveillance systems.

\section{Introduction}

The Syndromic Surveillance Consortium of Southeast Texas (SSCSeT) consists of 13 stakeholders who represent 19 counties or jurisdictions in the Texas Gulf Coast region and receives health data from over 100 providers. The Houston Health Department (HHD) maintains and operates the syndromic surveillance system for the Gulf Coast region since 2007. In preparation for Meaningful Use (MU) the HHD has adapted and implemented guidance and recommendations from Centers for Disease Control and Prevention, Office of National Coordinator for Health Information Technology and others. HHDs goal is to make it possible for providers meet MU specification by facilitating the transmission of health related data for syndromic surveillance. The timing of the transition into MU overlaps with the change in syndromic surveillance systems.

\section{Keywords}

Meaningful Use; Health information technology; Syndromic surveillance; local health department

\section{Acknowledgments}

Houston Health Department would like to acknowledge the contributions from Ali Momin (HHD IT), Kavitha Gantha (HHD IT), Chris Meredith (Texas DSHS/TALHO), Bill Stephens(Tarrant County Public Health Department), DaveHeinbaugh (Tarrant County Public Health Department), Texas S2 (Texas DSHS syndromic surveillance group), and the Syndromic Surveillance Consortium of Southeast Texas (SSCSeT), CDC ESSENCE.

\section{*Eunice R. Santos}

E-mail: eunice.santos@houstontx.gov 